\title{
Evaluation of Partially Purified Fractions of Crude Extracts of the Leaves of Morinda lucida (Benth.) and Datura stramonium (L.) for Suppression of Wood Damage by Subterranean Termites
}

\author{
Olufunmilayo Eunice Ajayi (Corresponding author) \\ Department of Biology, Federal University of Technology \\ P.M.B.704, Akure, Nigeria \\ Tel: 234-80-3578-5573 E-mail: ajfumeu@yahoo.co.uk \\ Christopher Olukayode Adedire \\ Department of Biology, Federal University of Technology \\ P.M.B.704, Akure, Nigeria \\ Tel: 234-80-3473-4923 E-mail: coadedire@yahoo.com \\ Labunmi Lajide \\ Department of Chemistry, Federal University of Technology \\ P.M.B.704, Akure, Nigeria \\ Tel: 234-80-3472-1396_E-mail: labunmilajide2000@yahoo.com
}

Received: March 14, 2011

doi:10.5539/jas.v4n5p125

\author{
Accepted: March 28, $2011 \quad$ Online Published: April 1, 2012 \\ URL: http://dx.doi.org/10.5539/jas.v4n5p125
}

\begin{abstract}
Ethanol extracts of Morinda lucida and Datura stramonium leaves were partitioned successively into petroleum ether, chloroform, ethyl acetate and methanol fractions. Each fraction was tested as wood preservative in-vivo at three different concentrations: $0.5 \%, 1.0 \%$ and $1.5 \% \mathrm{w} / \mathrm{v}$. Basudin ${ }^{\circledR}$, an organophosphate was used as standard. The extracts were applied on Triplochiton schleroxylon, a highly susceptible wood to termite infestation. The treated wood samples were exposed to termites for a period of twelve weeks. Observation was carried out weekly for signs of termite infestation. Weight loss in wood samples that were treated with fractions of $D$. stramonium leaf extract ranged from $8.20 \%-13.50 \%$ in petroleum ether fraction, $9.35 \%-19.99 \%$ in chloroform fraction, $6.15 \%$ and $10.89 \%$ in ethyl acetate fraction and $10.81 \%-20.27 \%$ in methanol fraction. Petroleum ether, chloroform, ethyl acetate and methanol soluble fractions of $M$. lucida gave a weight loss range of $5.25 \%-9.50 \%$, $6.28 \%-11.50 \%, 4.89 \%-6.70 \%$ and $8.50 \%-20.27 \%$ respectively. Ethyl acetate soluble fraction of the two plants appeared to be more potent in suppressing wood damage. Ethyl acetate soluble fraction of M. lucida was the most effective in damage reduction. Methanol fraction was the least effective with the highest recorded weight loss at all the treatment levels. The weight loss recorded at all treatment levels with fractions of M. lucida was lower compared to the result obtained in treatment with $D$. stramonium leaf fractions. The phytochemical screening, ${ }^{1} \mathrm{H}$ NMR and ${ }^{13} \mathrm{C}$ NMR suggest anthraquinone and scopoletin as the major components of ethyl acetate soluble fraction of M. lucida. This study reveals that the two plants have components that are potential wood preservatives.
\end{abstract}

Keywords: Datura stramonium, Morinda lucida, Triplochiton scleroxylon, Preservative, Termites, Infestation

\section{Introduction}

Plant-eating insects are a natural part of all ecosystems, but in farms, insects can be problematic. Over a thousand or more species in more than 370 genera and 90 families or more are pests of economically important crops (Culliney \& Grace, 2003). Belonging to these group of notorious insects are termites. Termites are small 
insects, found chiefly in the tropical areas, which are very destructive to timber (Harris, 1971). They are popularly called white ant, but they are not of the ant family (Harris, 1971; Umeh, 2000).

Termites are known to be of economic importance in the tropics. They mix soil matter and thereby increase their fertility (Umeh, 2003). However the affinity of termites for cellulose materials makes them deleterious to many plant species including timber, agricultural products and buildings in West Africa (Umeh, 2000) and the world at large.

One major agent causing the loss of wood both quantitatively and qualitatively is termite. In the United States alone, annual losses due to termite infestations are estimated at more than 800 million dollars (Meyer, 2005). The damage done by this group of social insects is overwhelming. Lewis (1997) puts his estimates at over 3 billion dollars in damage to wooden structures annually throughout the United States alone. Termite is one of the most economically important insects to humans and therefore need to be controlled. The control of termites is mainly by the use of synthetic chemicals. The attendant problems associated with the use of these chemicals such as high level of persistence in the environment, destruction of non-target organisms, non-availability, high cost, toxicity to personnel, level of education of the users is of great concern. Most of these chemicals are banned especially the organochlorines. As a result of this, research focus is on cheap, available, eco-friendly, host specific and cost effective means of controlling pests in the environment. Research efforts are currently on the use of plant products, such as powder, extracts and oils against insect pest (Adedire \& Ajayi, 1996).

Extract of some plants such as Veliveria nigeitana, Parkia clapertoniana, Cymbopogon nardus, C. schoenanthus, Digitaria sp, Pennicetum purpurerum, Chrysophylum albidum, Sanseviera libercum, Ocimum basilicum and oil of Elaeis guineensis Azadirachta indica, Chlorophora excelsa (Iroko), Nauclea diderrichii (Opepe), Mahogany, Pinus tree, Tectona grandis (Teak) have been reported to contain chemical substances the are repellent to termites (Benner, 1993; Delate \& Grace, 1995; Malaka, 1996; Oliver, 1960). Nicotine, pyrethrum and rotenone contain alkaloids that are toxic to termite (Ifebueme, 1977). This study seeks to evaluate $D$. stramonium and $M$. lucida plant extracts for suppression of wood damage by subterranean termites.

\section{Materials and Methods}

\subsection{Collection and Preparation of Plant Materials}

Plant materials, Morinda lucida and Datura stramonium leaves were obtained from villages near Akure in Ondo state, Nigeria. The leaves of these plants were air-dried in the laboratory at ambient tropical conditions and pulverized into fine powder using Kenwood electric blender and sieved with a 10-micron mesh size sieve (Adedire \& Ajayi, 1996). The fine powders were kept in dark airtight container in the freezer until used.

Triplochiton scleroxylon (Obeche) the wood substrate used in this study was obtained from Ibitoye saw-mill along Akure - Ilesha road, Akure, Ondo state, Nigeria. The wood was cut into 20 x 20 x $60 \mathrm{~mm}$ size and oven dried at $100^{\circ} \mathrm{C}$ to a constant weight $\left(\mathrm{W}_{1}\right)(\mathrm{ASTM}, 1974)$. This was kept in desiccators containing silica gel until used.

\subsection{Preparation of Plant Extracts}

Ethanolic extract of the plant materials were obtained by soaking the dried pulverized plant materials in absolute ethanol for $72 \mathrm{hrs}$. The solution was filtered and the filtrate was concentrated in rotary evaporator. The slurry obtained was freeze-dried. The freeze-dried sample was partially purified into Petroleum ether, Chloroform, Ethyl acetate and Methanol fractions by adding these solvent successively using separating funnel (Harborne, 1984). The respective solvent fractions were concentrated in rotary evaporator and freeze-dried. The dried powder obtained were kept in brown bottles and kept in freezer until required.

\subsection{In Vivo Trial}

Each solvent fraction obtained was tested at $0.5 \%, 1.0 \%$ and $1.5 \% \mathrm{w} / \mathrm{v}$ using the respective solvent as the diluents. The solution was applied on the weighed (initial weight $\mathrm{W}_{1}$ ) wood samples by brushing. Standard control using diazinon $\left(\right.$ Basudin $\left.^{\circledR}\right)$, untreated and solvent controls were set up. Diazinon solution was prepared according to the manufacturers' specification. Untreated samples were also suspended from the ground to account for the weight loss due to environmental factors. All treatments were replicated four times. Each of the treated wood samples was positioned $30 \mathrm{~cm}$ apart on the field for a period of twelve weeks. Observation was carried out on weekly bases for signs of infestation. At the expiration of the period of trial, the remains of the wood samples were cleaned, re-dried to constant weight (final weight $\mathrm{W}_{2}$ ) to obtain weight difference from initial weight. The percentage difference (\% weight loss) between the initial and final weight was used as index of susceptibility or protectant-ability of the extracts as follows: 


$$
\% \text { Weight loss }=\frac{\mathrm{W}_{1}-\mathrm{W}_{2}}{\mathrm{~W}_{1}} \times \frac{100}{1}
$$

\subsection{Phytochemical Screening of Ethanol Extract and Solvent Partitioned Fractions of M. lucida}

The ethanolic extract and solvent partitioned fractions (petroleum ether, chloroform, ethyl acetate and methanol soluble fractions of ethanol extract of the leaf) of M. lucida was screened for the presence of alkaloids, saponins, tannins, anthraquinones, cardiac glycosides and flavonoids according to the methods described by Sofowora (1993).

\subsection{Chromatographic Separation of Ethyl Acetate Soluble of M. lucida}

The ethyl acetate fraction was fractionated by Accelerated Gradient Chromatography (AGC) on silica gel employing n-hexane-dichloromethane and dichloromethane-ethyl acetate gradient elution from 100\% n-hexane to $100 \%$ dichloromethane (DCM) to 1:1 DCM: EtOAc. Collected fractions were developed on precoated TLC plate.

Vanillin/concentrated Sulphuric acid reagent (V/S spray) was used as chemical spray reagent. Fractions which showed similar TLC characteristics were bulked appropriately and concentrated in vacuo at $40^{\circ} \mathrm{C}$. The concentrated fractions were further purified using Vacuum Liquid Chromatograghy (VLC) and subjected to Nuclear Magnetic Resonance and Infra Red spectroscopy for characterization of the chemical components.

\section{Results}

\subsection{Effect of Partially Purified Fractions of D. stramonium and M. lucida on Wood Infestation by Termites}

The results of in-vivo evaluation of bioactivity of partially purified fractions of D. stramonium and M. lucida as wood protectants are shown in Tables 1 and 2 . Weight reduction in wood samples that were treated with purified fractions of D. stramonium leaves ranged between $8.20 \%$ and $13.50 \%$ in wood treated with petroleum ether soluble fraction, $9.35 \%$ and $19.99 \%$ in wood treated with chloroform soluble fraction, $6.15 \%$ and $10.89 \%$ in wood treated with ethyl acetate soluble fraction and between $10.81 \%$ and $20.27 \%$ in wood treated with methanol soluble fraction. Petroleum ether, chloroform, ethyl acetate and methanol soluble fractions of M. lucida gave a weight loss range of 5.25\%- 9.50\%, 6.28\%-11.50\%, 4.89\%-6.70\% and 8.50\%-20.27\% respectively. Petroleum ether, chloroform, ethyl acetate and methanol soluble fractions of the leaf extract of $M$. lucida resulted in $5.25 \%$, $6.28 \%, 4.89 \%$ and $8.25 \%$ weight loss respectively while Petroleum ether, chloroform, ethyl acetate and methanol soluble fractions of the leaf extracts of $D$. stramonuim resulted in $8.20 \%, 9.35 \%, 6.15 \%$ and $10.81 \%$ weight loss respectively at the highest treatment level (1.5\%) applied. Ethyl acetate soluble fraction of the two plants appeared to be more potent as the percentage weight loss recorded in wood treated with it was significantly $(\mathrm{P}<0.05)$ lower compared to other soluble fractions. Next to ethyl acetate in wood damage reduction is petroleum ether soluble fraction. Methanol fraction was the least effective with the highest recorded weight loss at all the treatment levels. The weight loss recorded at all treatment levels with fractions of M. lucida was lower compared to the result obtained in treatment with D. stramonium leaf fractions.

\subsection{Phytochemical Constituents of Ethanol Extract of M. lucida}

The results of the screening for secondary metabolites are presented in Table 3. M. lucida contains alkaloids, saponins, tannins, cardiac glycoside and flavonoids. All the metabolites found in the ethanol extract were also found in ethyl acetate soluble fraction.

The infrared, ${ }^{1} \mathrm{H}$ NMR and ${ }^{13} \mathrm{C}$ NMR spectra of fraction of ethyl acetate soluble suggest strongly that it contains scopoletin and anthraquinones derivatives. The infrared spectrum revealed the presence of aromatic $\mathrm{C}-\mathrm{H}$ stretches. Carbonyl frequencies at $1650 \mathrm{~cm}^{-1}$ and $1710 \mathrm{~cm}^{-1}$ which are characteristics of anthraquinones were also observed.

\section{Discussion}

The different soluble fractions of $M$. lucida and D. stramonium were effective as antifeedants against termites. The lowest weight loss was recorded in the woods treated with these soluble fractions compared to untreated and solvent treated samples. The effectiveness is concentration dependent with ethyl acetate soluble fractions being the most effective fractions of the two plants' leaf extracts.

Plants produce some natural products that are either toxic to animals or useful as therapeutic agents. Some of these products are synthesized by the plants while some are products of metabolism. These compounds include tannins, saponins, anthraquinones, alkaloids, flavonoids, cardiac glycosides and phlobatannins. These compounds are responsible for the toxicity of plant materials to insects. M. lucida was reported to contain alkaloids, tannins, flavonoids, anthraquinones and saponins (Nweze et al., 2004; Akinyemi et al., 2005). The 
phytochemical screening in this study confirms this. The effectiveness of the plant could be attributed to the combined activities of its components such as tannins, alkaloids, flavonoids, anthraquinones and glycosides.

Ethyl acetate soluble fraction of $M$. lucida crude extract was the most effective of the extracts resulting in the lowest weight loss of the treated wood samples. Ethyl acetate is known for extraction of flavonoids (Harbone, 1984). Flavonoids exhibit a wide range of biological properties including antimicrobial, insecticidal and oestrogenic activities. Important phenolics in terms of insecticidal, repellent and feeding deterrent functions are flavonoids which are characteristics of higher plants (Dakora, 1995; El-Fadaly and El-Badrawy, 2001; Stephen et al., 2003; Upasani et al., 2003; Jung et al., 2005; Marcio, 2007; Georges et al., 2008). An insecticidal isoflavon glycoside isolated from roots of Maackia ammurensis was reported to have insecticidal activities against brown planthopper female adults by Hasik et al. (1991). El-Fadaly and El-Badrawy (2001) reported flavonoids obtained from honey bees propolis, a sticky amalgamation of plant resins collected by Apis mellifera to have antimicrobial, insecticidal and phytotoxic properties. Excellent insecticidal activities of flavonoids obtained from aqueous leaf extract of Ricinus communis against Callosobruchus chinensis was reported by Upasani et al. (2003). Flavonoids isolated from aqueous foliar extract of Annona squamosa was reported to have $80 \%$ insecticidal activity against $C$. chinensis (Kotkar et al., 2002). Stephen et al. (2003) reported toxicity and repellency/feeding deterrence of leaves of the tropical legume, Tephrosia candida to diaprepes root weevil, Diaprepes abbreviatus.

D. stramonium, like Atropa belladonna and Mandrake belonging to the same family called Solanaceae are known to be toxic due to alkaloid contents (Dutta, 1995). All parts of D. stramonium commonly known as Devil's trumpet or thorn apple had been reported to contain toxic materials due to high level of alkaloids. The primary alkaloids are the atropines, scopolamine and daturine (Dutta, 1980). The effectiveness of these plants can be attributed to the toxic components in them.

This study revealed scopoletin and anthraquinone as the major constituents of the most potent plant extracts used. Scopoletin, umbelliferone and esculetin are the widespread coumarins in nature. Coumarin (anhydride of o-coumaric acid) is white, crystalline lactone, obtainable naturally from plants or produced synthetically from an amino acid, phenylalanine. It inhibits the hepatic synthesis of the vitamin $\mathrm{K}$-dependent coagulation factors. Coumarin derivatives are used widely as anticoagulants (warfarin) for the treatment of disorders in which there is excessive or undesirable clotting, such as thrombophlebitis, pulmonary embolism, and certain cardiac conditions. Coumarin has blood thinning activities. It increases the blood flow in veins and decreases capillary permeability. Coumarin derivatives are used as rodenticides due to the property of causing fatal hemorrhaging (Obasi, 1994).

The plants used in this study are readily available in the environment and are biodegradable; hence, they are potential sources of biocontrol agents for suppression of wood damage by subterranean termites.

\section{References}

Adedire, C. O. \& Ajayi, T. S. (1996). Assessment of the insecticidal properties of some plant extracts as grain protectants against the maize weevil, Sitophilus zeamais (Motsch). Nigerian Journal of Entomology, 13, 93-101.

Akinyemi K. O., Mendie, V. E, Smith S. T., Oyefolu, A. O. \& Coker, A. O. (2005). Screening of some medicinal plants used in southwest Nigerian traditional medicine for anti-Salmonella typhi activity. Journal of Herbal Pharmacoth, 5 (1), 45-60.

ASTM. (1974). Amercan Standard for Testing Materials. DB. Pp 345-374.

Benner, J. P. (1993). Pesticidal compounds from higher plants. Pesticide Science, 39, 95-102. http://dx.doi.org/10.1002/ps.2780390202

Culliney, O. \& Grace, J. K. (2003). Developmental stages and biological potential of a reduviid predator, Acamthapsi pedestris, against termites on groundnut. International Aradus Newsletter, 15, 57-59.

Dakora, F. D. (1995). Plant flavonoids: Biological molecules for usefull exploitation. Australian Journal of Plant Physiology, 22(1), 87-99. http://dx.doi.org/10.1071/PP9950087

Delate, K. M. \& Grace, J. K. (1995). Susceptibility of neem to attack by the Formosan Subterranean Termite, Coptotermes formosanus Shir. (Isoptera: Rhinotermitidae). Journal of Applied Entomology, 119, 93-95. http://dx.doi.org/10.1111/j.1439-0418.1995.tb01250.x

Dutta, A. O. (1980). A Class Book of Botany. $6^{\text {th }}$ Edition. Pg 502.

Dutta, A. C. (1995). Botany for Degree Students. Revised edition; Oxford University Press. Pp 48. 
El-Fadaly, H. \& El-Badrawy, E. E. Y. (2001). Flavonoids of propolis and their antibacterial activities. Pakistan Journal of Biological Sciences, 4(2), 204-207. http://dx.doi.org/10.3923/pjbs.2001.204.207

George, K., Jayaprakasam, B., Dalavoy, S. S. \& Nair, M. G. (2008). Pest-management activities of plant extracts and anthraquinones from Cassias nigricans from Burkina Faso. The New England Journal of Medicine, 99(6), 2037-45.

Harbone, J. B. (1984). Phytochemistry Methods: A guide to Modern Techniques of Plant Analysis $2^{\text {nd }}$ Edition Chapman and Hall, London, pp 20-126.

Harris, W. V. (1971). Termites, their recognition and control. Longman Green and Co. Ltd. London (1) 174pp.

Hasik, Y., Sangkyun, L., Jin-Ho, C. \& Hunseung, O. (1991). Insecticidal isoflavon glycoside from Maackia amurensis. Archives of Pharmacological Research, 14(2), 105-108. http://dx.doi.org/10.1007/BF02892012

Ifebueme, S. C. (1977). Preservative treatment of timbers by simple methods: Proceeding of International Workshop on Wood Preservation. FRIN Ibadan Nigeria. $7^{\text {th }}-12^{\text {th }}$ November, 1977.

Jung, H. P., Barbara, M. G. \& Ramaswamy, G. N. (2005). Naturally occurring quinines and flavonoid dyes for wool: Insect feeding deterrents. Journal of Applied. Polymer Science, 98(1), 322-328. http://dx.doi.org/10.1002/app.22039

Kothar, H. M., Mendki, P. S., Sadan, S. V. G. S., Jha, S. R., Upasani, S. M. \& Maheshwari, V. L. (2002). Antimicrobial and pesticidal activity of partially purified flavonoids of Annona squamosa. Pest Management Science, 58(1), 33-37. http://dx.doi.org/10.1002/ps.414

Lewis, V. R. (1997). Alternative control strategies for termites. Journal of Agricultural Entomology, 14, 291-307.

Malaka, S. L. O. (1996). Termites in West Africa. $1^{\text {st }}$ edition. University of Lagos press Pp 1-151.

Marcio, D. M., Marcelo, C. P., Luiz, L. B., Raul, N. C., Mateus, R., Gerson, S. \& Julio, C. M. (2007). Plant compounds insecticide activity against coleoptera pests of stored products. Pesq. Agrop. Brasil, 42(7). http://dx.doi.org/10.1590/50100

Meyer, J. R. (2005). Isoptera. http://www.cals.ncsu.edu/course/ent425/compedium/ termitehtml. (accessed 25.07.2009).

Nwese, E. I., Okafor, J. I. \& Njoku, O. (2004). Antimicrobial activities of methanolic extracts of Trema guineensus (Schunm and Thorn ) Morinda lucida (Benth) used in Nigeria. Bio-research, 2(1), 39-46.

Obasi, S. C. (1994). Effects of single oral doses of scopoletin and aflatoxin B1 on the clotting time, serum cholesterol and phospholipid levels of chicks. Indian Journal of Physiology and Pharmacology, 38(2), 89-94.

Oliver, B. (1960). Nigeria's useful plants. Nigerian Field, 25(4), 174-192.

Stephen, L., Lapointe, C. L. M \& Wayne, B. H. (2003). Toxicity and Repellency of Tephrosia candida to larval and adult diaprepes root weevil (Coleoptera: Curculionidae). Journal of Economic Entomology, 96 (3), 811-816. http://dx.doi.org/10.1603/0022-0493-96.3.811

Trease, G. E. \& Evans, C. W. (1985). A textbook of Pharmacology, $13^{\text {th }}$ Edition ELBS 1 Bailliere Tindall, London, pp. 378-386.

Umeh, V. C. (2000). Advances in the control of termite pests of some tropical crops using naturally occurring pesticides. Paper presented at $14^{\text {th }}$ Africa Association of Insect Scientists and the $9^{\text {th }}$ Crop Protection society of Ethiopia joint conference, June 4-8 2001, Ethiopia an Agricultural Research organization Addis Ababa.

Umeh, V. C. (2003). An appraisal of farmers termite control methods in some traditional cropping system of West Africa. Nigerian Journal of Entomology, 20, 25-39.

Upasani, S. M., Kotkar, H. M., Mendki, P. S. \& Maheshwari, V. L. (2003). Partial characterization and insecticidal properties of Ricinus communis (L.) foliage flavonoids. Pest Management Science, 59(12), 1349-1354. http://dx.doi.org/10.1002/ps.767 
Table 1. Effect of partially purified fractions of Datura stramonium leaf extract on wood infestation by subterranean termites (Mean $\% \pm$ S.E)

Treatment Concentration

\begin{tabular}{lllll}
\multicolumn{1}{c}{$(\% \mathrm{w} / \mathrm{v})$} & ${ }^{* *}$ PESF & \multicolumn{1}{c}{ CSF } & EASF & MSF \\
\hline Untreated & $90.40^{\mathrm{f}} \pm 0.00$ & $91.20^{\mathrm{e}} \pm 0.00$ & $91.27^{\mathrm{e}} \pm 0.00$ & $94.11^{\mathrm{f}} \pm 0.00$ \\
Solvent control & $83.42^{\mathrm{e}} \pm 0.24$ & $91.11^{\mathrm{e}} \pm 0.00$ & $90.69^{\mathrm{e}} \pm 0.00$ & $89.89^{\mathrm{e}} \pm 0.00$ \\
0.5 & $13.50^{\mathrm{d}} \pm 0.11$ & $19.99^{\mathrm{d}} \pm 0.00$ & $10.89^{\mathrm{d}} \pm 0.00$ & $20.27^{\mathrm{d}} \pm 0.00$ \\
1.0 & $11.18^{\mathrm{c}} \pm 0.00$ & $15.18^{\mathrm{c}} \pm 0.00$ & $8.92^{\mathrm{c}} \pm 0.00$ & $14.22^{\mathrm{c}} \pm 0.00$ \\
1.5 & $8.20^{\mathrm{b}} \pm 0.00$ & $9.35^{\mathrm{b}} \pm 0.00$ & $6.15^{\mathrm{b}} \pm 0.00$ & $10.81^{\mathrm{b}} \pm 0.00$ \\
Diazinon $(0.24)$ & $3.73^{\mathrm{a}} \pm 0.00$ & $3.73^{\mathrm{a}} \pm 0.00$ & $3.73^{\mathrm{a}} \pm 0.00$ & $3.73^{\mathrm{a}} \pm 0.00$ \\
\hline
\end{tabular}

Means followed by the same letter within column are not significantly different $(\mathrm{P}>0.05)$ from each other using New Duncan's Multiple Range Test

** PESF (Petroleum ether soluble fraction)

CSF (Chloroform soluble fraction)

EASF (Ethyl acetate soluble fraction)

MSF (Methanol soluble fraction)

Table 2. Effect of partially purified fractions of Morinda lucida leaf extract on wood infestation by subterranean termites (Mean $\% \pm$ S.E.)

Treatment Concentration

\begin{tabular}{lllll}
\multicolumn{1}{c}{$(\% \mathrm{w} / \mathrm{v})$} & $* *$ PESF & \multicolumn{1}{c}{ CSF } & \multicolumn{1}{c}{ EASF } & MSF \\
\hline Untreated & $90.40^{\mathrm{f}} \pm 0.00$ & $91.20^{\mathrm{e}} \pm 0.00$ & $91.27^{\mathrm{e}} \pm 0.00$ & $94.11^{\mathrm{f}} \pm 0.00$ \\
Solvent control & $83.42^{\mathrm{e}} \pm 0.24$ & $91.11^{\mathrm{e}} \pm 0.00$ & $90.69^{\mathrm{e}} \pm 0.00$ & $89.89^{\mathrm{e}} \pm 0.00$ \\
0.5 & $9.50^{\mathrm{d}} \pm 0.74$ & $11.50^{\mathrm{d}} \pm 0.44$ & $6.70^{\mathrm{d}} \pm 0.20$ & $20.27^{\mathrm{d}} \pm 0.10$ \\
1.0 & $7.00^{\mathrm{c}} \pm 0.41$ & $8.50^{\mathrm{c}} \pm 0.21$ & $5.00^{\mathrm{b}} \pm 0.49$ & $10.22^{\mathrm{c}} \pm 0.19$ \\
1.5 & $5.25^{\mathrm{b}} \pm 0.14$ & $6.28^{\mathrm{b}} \pm 0.08$ & $4.89^{\mathrm{ab}} \pm 0.18$ & $8.50^{\mathrm{b}} \pm 0.02$ \\
Diazinon $(0.24)$ & $3.73^{\mathrm{a}} \pm 0.00$ & $3.73^{\mathrm{a}} \pm 0.00$ & $3.73^{\mathrm{a}} \pm 0.00$ & $3.73^{\mathrm{a}} \pm 0.00$ \\
\hline
\end{tabular}

Means followed by the same letter within column are not significantly different $(\mathrm{P}>0.05)$ from each other using New Duncan's Multiple Range Test

** PESF (Petroleum ether soluble fraction)

CSF (Chloroform soluble fraction)

EASF (Ethyl acetate soluble fraction)

MSF (Methanol soluble fraction)

Table 3. Phytochemical constituents of ethanol extract and the partially purified fractions of ethanol extract of the leaf of Morinda lucida

\begin{tabular}{llllll}
\hline Metabolites & EtOH & PESF & CSF & EASF & MSF \\
\hline Alkaloids & + & - & - & + & - \\
Saponins & + & + & + & + & + \\
Tannins & + & - & - & + & - \\
Anthraquinones & + & - & - & & + \\
Flavonoids & + & + & - & - \\
Cardiac glycosides & & - & - & + & - \\
Cardenolides & - & - & - & + & + \\
Steroidal ring & + & - & - & & - \\
Deoxy sugar & + & - & & & + \\
\hline
\end{tabular}

+ Positive

- Negative

$\mathrm{EtOH}=$ Ethanol extract

PES $=$ Petroleum ether soluble fraction

$\mathrm{CSF}=$ Chloroform soluble fraction

EASF $=$ Ethyl acetate soluble fraction

$\mathrm{MSF}=$ Methanol soluble fraction 